\title{
Application of Kahoot Media to Improve Student Learning Outcomes in Finding Vocabulary and Meaning of Vocabulary Relating to Social Life
}

\section{Dwi Susanti}

SD Negeri Sukareja 02

susantidwi231@gmail.com

\section{Article History}

accepted 01/11/2020

\begin{abstract}
The purpose of this study was to improve student learning outcomes in finding vocabulary and vocabulary meanings related to social life. This research is a classroom action research (PTK) which is carried out in three cycles, each cycle consisting of planning, implementation, observation, and reflection stages. The subjects of this study were students of class II SD Negeri Sukareja 02 in the 2020/2021 school year, totaling 14 students. Data collection techniques using tests. Data analysis includes data reduction, data presentation, and drawing conclusions. Research shows that the application of Kahoot media can improve student learning outcomes in the material of finding vocabulary and meaning related to social life in class II SD Negeri Sukareja 02 in the academic year 2020/2021 as evidenced by the percentage of completeness of learning outcomes in cycle I of $71 \%$, cycle II of $86 \%$, and becomes $93 \%$ in cycle III.
\end{abstract}

Keywords: Kahoot, Vocabulary, Students

\begin{abstract}
Abstrak
Tujuan penelitian ini adalah meningkatkan hasil belajar siswa pada materi menemukan kosakata dan makna kosakata berkaitan kehidupan sosial. Penelitian ini merupakan penelitian tindakan kelas (PTK) yang dilaksanakan dalam tiga siklus, setiap siklus terdiri dari tahap perencanaan, pelaksanaan, observasi, dan refleksi. Subjek penelitian ini adalah peserta didik kelas II SD Negeri Sukareja 02 tahun pelajaran 2020/2021 yang berjumlah 14 peserta didik. Tekni pengumpulan data menggunakan tes. Analisis data meliputi reduksi data, penyajian data, dan penarikan kesimpulan. Penelitian menunjukkan bahwa penerapan media Kahoot dapat meningkatkan hasil belajar siswa pada materi menemukan kosakata dan makna kosakata berkaitan kehidupan sosial di kelas II SD Negeri Sukareja 02 tahun pelajaran 2020/2021yang dibuktikan dengan persentase ketuntasan hasil belajar pada siklus I sebesar $71 \%$, siklus II sebesar $86 \%$, dan menjadi $93 \%$ pada siklus III.
\end{abstract}

Kata kunci: Kahoot, Kosakata, Siswa

Social, Humanities, and Education Studies (SHEs): Conference Series https://jurnal.uns.ac.id/shes 


\section{PENDAHULUAN}

Pandemi Covid-19 yang melanda dunia sangat mempengaruhi kehidupan manusia. Tidak hanya mempengaruhi dalam bidang kesehatan, tetapi juga bidang ekonomi dan pendidikan. Berdasarkan Surat Edaran Menteri Pendidikan dan Kebudayaan Nomor 4 Tahun 2020 ini mengatur tentang Pelaksanaan Kebijakan Pendidikan dalam Masa Darurat Penyebaran Covid-19 (https://www.kemdikbud.go.id). Surat edaran ini mengharuskan peserta didik untuk mengikuti kegiatan pembelajaran jarak jauh (PJJ). Oleh karena itu, guru dan peserta didik dituntut untuk menguasai berbagai aplikasi pembelajaran online. Keuntungan pembelajaran dengan teknologi dapat menciptakan iklim belajar yang efektif bagi siswa yang lamban dalam pembelajaran, merangsang siswa dalam mengerjakan latihan dan dapat menyesuaikan kecepatan kecepatan belajar dapat sesuai dengan kemampuan siswa (Made Wena, 2011).

Namun, penggunaan media pembelajaran daring yang kurang menarik merupakan salah satu faktor penyebab kurang maksimalnya hasil belajar menemukan kosakata dan makna kosakata yang berkaitan kehidupan sosial di kelas II SDN Sukareja 02. Guru melakukan kegiatan pembelajaran berbasis daring dalam bentuk yang kurang menarik minat peserta didik, sehingga banyak peserta didik yang tidak aktif mengikuti pembelajaran dan mempengaruhi terhadap hasil belajarnya.

Berdasarkan hasil pengamatan hasil belajar siswa kelas II SDN Sukareja 02 pada mata pelajaran Bahasa Indonesia materi menemukan kosakata dan makna kosakata yang berkaitan kehidupan sosial yaitu dari 27 siswa, terdapat 20 siswa mendapat nilai $\geq 70$, sedangkan 7 siswa mendapat nilai $\leq 70$. Dapat disimpulkan bahwa hanya 65\% siswa lulus KKM dan 35\% tidak lulus KKM .

Ada beberapa penyebab rendahnya hasil belajar materi menemukan kosakata dan makna kosakata berkaitan kehidupan sosial, diantaranya : (1) Guru masih menggunakan media pembelajaran daring yang kurang tepat; (2) Guru tidak menguasai media pembelajaran daring; (3) Siswa kurang aktif dalam pembelajaran daring.

Berdasarkan hasil fakta di kelas II SDN Sukareja 02, maka perlu penerapan media pembelajaran yang tepat sebagai proses pembelajaran Bahasa Indonesia. Salah satu media pembelajaran yang menarik adalah Kahoot. Dengan menggunakan Kahoot guru dapat menciptakan suasana belajar mengajar yang aktif dan menyenangkan karena salah satu teknik pembelajaran game based lerning (pembelajaran berbasis permainan). Pembelajaran berlandasan permainan merupakan alat yang dapat membantu peserta didik dalam menyelesaikan masalah, meningkatkan pemikiran kritis dan membuat sebuah penilaian dalam proses pembelajaran (Ryan Dellos, 2015).

Kahoot merupakan salah satu platform permainan online yang bisa diterapkan sebagai media pembelajaran. Pada fitur quiz Kahoot, akun peserta/ siswa dapat menjawab melalui perangkat yang telah terkoneksi dengan internet (smartphone/laptop/tablet) sesuai dengan pertanyaan yang ditampilkan di layar oleh akun guru (kahoot.com, 2018). Berdasarkan penelitian (Ebru, 2017) tentang perbandingan penggunaan 3IRS (Interactive Respoce System) yaitu Kahoot, socrative, dan plicker menunjukkan bahwa sebanyak $75 \%$ siswa menyatakan Kahoot menyenangkan jika digunakan dalam pembelajaran. Media Kahoot terbukti membuat suasana belajar lebih menyenangkan, siswa lebih aktif berpartisipasi dalam proses pembelajaran (Nur Hafidhotul IImiyah dan Meini Sondang Sumbawati, 2019). Hal ini sejalan dengan hasil penelitian (Rafnis, 2020) yang menyatakan bahwa penggunaan media Kahoot dalam pembelajaran sangat menarik, efektif, dan menyenangkan sehingga dapat meningkatkan semangat dan keaktifan peserta didik.

Berdasarkan uraian di atas, penulis akan mencoba melakukan penelitian dengan judul Penerapan Media Kahoot untuk Meningkatkan Hasil Belajar Siswa pada 
Materi Menemukan Kosakata dan Makna Kosakata Berkaitan Kehidupan Sosial di Kelas II SD Negeri Sukareja 02 tahun pelajaran 2020/2021. Tujuan penelitian ini adalah meningkatkan hasil belajar siswa pada materi menemukan kosakata dan makna kosakata berkaitan kehidupan sosial.

\section{METODE}

Penelitian ini merupakan penelitian tindakan kelas (PTK) kolaboratif yang dilaksanakan dalam tiga siklus, setiap siklus terdiri dari tahap perencanaan, pelaksanaan, observasi, dan refleksi. Subjek penelitian ini adalah peserta didik kelas II SD Negeri Sukareja 02 tahun pelajaran 2020/2021 yang berjumlah 14 siswa.

Data yang dianalisis berupa data kualitatif yaitu hasil belajar Bahasa Indonesia peserta didik. Teknik pengumpulan data menggunakan tes. Uji validitas data menggunakan triangulasi teknik dan triangulasi sumber. Analisis data meliputi reduksi data, penyajian data, dan penarikan kesimpulan.

\section{HASIL DAN PEMBAHASAN}

Hasil penelitian menunjukkan peningkatan hasil belajar pada materi menemukan kosakata dan makna kosakata berkaitan kehidupan sosial. Terlihat pada tabel berikut.

Tabel 1. Peningkatan Hasil Belajar

\begin{tabular}{lcccccc}
\hline \multirow{2}{*}{ Nilai } & \multicolumn{2}{c}{ Siklus I } & \multicolumn{2}{c}{ Siklus II } & \multicolumn{2}{c}{ Siklus III } \\
\cline { 2 - 7 } & $\mathbf{f}$ & $\%$ & $\mathbf{f}$ & $\%$ & $\mathbf{f}$ & $\%$ \\
\hline 100 & 1 & 7 & 2 & 14 & 3 & 22 \\
\hline 80 & 9 & 64 & 10 & 71 & 10 & 71 \\
\hline 60 & 4 & 29 & 2 & 15 & 1 & 7 \\
\hline 40 & 0 & 0 & 0 & 0 & 0 & 0 \\
\hline 20 & 0 & 0 & 0 & 0 & 0 & 0 \\
\hline Jumlah & 1.040 & & 1.120 & & 1.160 & \\
\hline Rata-rata & 74,29 & & 80 & & 82,86 & \\
\hline Tuntas & 10 & $71 \%$ & 12 & $86 \%$ & 13 & $93 \%$ \\
\hline
\end{tabular}

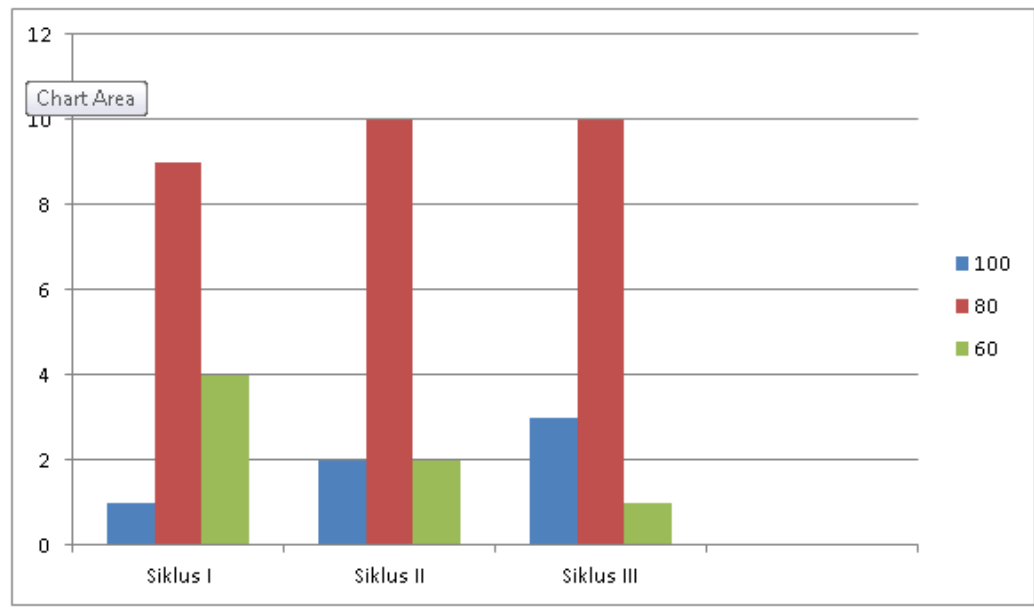

Gambar 1. Hasil Belajar 
Peningkatan hasil belajar Bahasa Indonesia pada materi menemukan kosakata dan makna kosakata berkaitan kehidupan sosial diukur dengan menggunakan teknik tes hasil belajar dengan instrumen lembar soal evaluasi. Teknik pengumpulan data hasil belajar peserta didik diterapkan di setiap pertemuan setelah dilakukan kegiatan pembelajaran. Aspek yang diukur yaitu aspek kognitif atau pengetahuan yang terdiri dari menganalisis (C4) dan menemukan (C4) yang diukur berdasarkan hasil evaluasi setelah mengikuti pembelajaran dengan menggunakan media Kahoot pada materi menemukan kosakata dan makna kosakata berkaitan kehidupan sosial.

Penggunaan media Kahoot dalam pembelajaran Bahasa Indonesia dapat meningkatkan hasil belajar peserta didik di kelas II SD Negeri Sukareja 02. Pada hasil penilaian sebelumnya persentase ketuntasan belajar hanya $65 \%$. Setelah dilakukan tindakan, persentase ketuntasan belajar meningkat menjadi $71 \%$. Pada siklus II terjadi peningkatan kembali yang mencapai $86 \%$. Peningkatan kembali terjadi pada siklus III yaitu sebesar 93\% dengan KKM 70 sehingga pelaksanaan tindakan dapat dihentikan.

Berdasarkan tabel hasil belajar peserta didik terhadap penggunaan media Kahoot dapat dilihat bahwasanya peserta didik sangat tertarik untuk menggunakan platform Kahoot sebagai kuis dalam pembelajarannya. (Luqman et al., 2017) menyatakan bahwa pembelajaran yang menyenangkan, menarik minat dan tidak membosankan peserta didik, salah satu awal agar pembelajaran menjadi bermakna yang pada akhirnya dapat meningkatkan hasil belajar peserta didik.

\section{SIMPULAN}

Penggunaan media Kahoot dalam pembelajaran menemukan kosakata dan makna kosakata yang berkaitan dengan kehidupan sosial sangat memotivasi siswa dalam belajar. Media Kahoot dapat menarik minat dan keaktifan siswa dalam kegiatan pembelajaran. Hal ini sangat berpengaruh terhadap peningkatan hasil belajar siswa yang dengan ketuntasan hasil belajar peserta didik pada siklus I sebesar $71 \%$, meningkat menjadi $86 \%$ pada siklus II, dan lebih meningkat pada siklus III menjadi $93 \%$.

Berdasarkan hasil penelitian tindakan kelas tersebut, guru dapat melibatkan siswa dalam pemanfaatan kemajuan teknologi dengan bantuan media Kahoot agar siswa lebih menguasai materi pembelajaran, sehingga hasil belajarnya meningkat. Sekolah hendaknya memotivasi guru untuk terus berusaha memanfaatkan teknologi dalam kegiatan pembelajaran yang berdampak pada peningkatan hasil belajar siswa.

\section{DAFTAR PUSTAKA}

Ebru, D. S. (2017). Ask Response Play Learns : Student's View On Gamification Based Interactive Response System. Journal of Education Ans Instructional Studies Un The World, Vol 7, Issue: 3, ISSN: 2146-7463.

Ilmiyah, N. H. \& Sumbawati, M. S. (2019). Pengaruh Media Kahoot dan Motivasi Belajar Terhadap Hasil Belajar Siswa. JIEET: Volume 03 Nomor 01, 2019

Kahoot. (2015). What is Kahoot. Dipetik Oktober 19, 2020, dari Kahoot: https://kahoot.com/what-is-kahoot/.

Luqman, M., Hakim, I., Saad, M., Teknologi, U., Zulfadhli, A., Universiti, N., ... Saad, M. (2017). Penggunaan Aplikasi Kahoot! Dalam Pembelajaran Bahasa Arab: Satu Tinjauan. In Sembara 2017.

Made Wena. (2011). Strategi Pembelajaran Inovatif Kontemporer. Bumi Aksara.

Rafnis. (2020). Pemanfaatan Platform Kahoot Sebagai Media Pembelajaran Interaktif. https://ejournal.unp.ac.id/index.php/e-tech/article/view/101336 
Ryan Dellos. (2015). Kahoot! A digital game resource for learning. In International Journal of Instructional Technology and Distance Learning Vol 12 (pp. 49-52). Retrieved from https://scholar.google.co.kr/citations?user=irAHXE4AAAAJ\&hl=en\#d=gs md cit $\underline{\mathrm{a}-}$ d\&p=\&u=\%2Fcitations\%3Fview op\%3Dview citation\%26hl\%3Den\%26user\%3 DirAHXE4AAAAJ\%26citation for view\%3DirAHXE4AAAAJ\%3Au5HHmVD uO 8C\%26tzom\%3D-420

SE Mendikbud: Pelaksanaan Kebijakan Pendidikan dalam Masa Darurat Penyebaran Covid-19. (2020). https://ww.kemdikbud.go.id 